\title{
Análise do discurso de Bobók, de Dostoiévski
}

Danilo Chiovatto SERPA

(Universidade de São Paulo)

RESUMO: Propomos uma análise do discurso do conto Bobók, de Dostoiévski, com base na semiótica francesa, com atenção especial naquilo que nela é definido como categoria de presença. As transgressões de tempo, espaço e pessoa sustentam a representação polifônica, juntamente com a carnavalização e a sátira menipéia.

PALAVRAS-CHAVE: Bobók; polifonia; carnavalização

ABSTRACT: This paper proposes an analysis of the short story Bobok, by Dostoyevsky, based on the French semiotics point of view, mainly concerning the category of presence. Time, space and person transgressions support the polyphonic representation along with “carnivalization” and the Menippean satire.

KEYWORDS: Bobok; polyphony; carnivalization 
A ntes do início da narração de Bobók (1873), há uma indicação: "Desta vez eu publico as 'Notas de uma pessoa'. Essa pessoa não sou eu; é outra bem diferente. Acho que não é mais necessário nenhum prefácio (Dostoiévski, 2005:15)”. Ao que, segue-se a narração em primeira pessoa de Ivan Ivanovitch. Vozes que se entrecruzam na constituição do ator-narrador, que "não sou eu, é outra bem diferente".

Seguindo a tipologia de narradores proposta por Barros (2001:87), podemos enquadrar a narrativa como:

narrador $=$ observador $=$ actante narrativo

O fato de $o$ ator narrador, que tem a dimensão pragmática da verbalização, ser o ator-observador, que tem a dimensão cognitiva, e, além de tudo, ser um actante narrativo, leva-nos a atentar para o estilo da narração. E também para a própria construção dos personagens, e principalmente do personagem que é o narrador, pois é a recriação de si mesmo através da linguagem. Atentar para a capacidade de se constituir através do outro: relação com outros personagens em uma narrativa polifônica, em que eles têm vozes plenivalentes, e através também do outro do discurso, o "tu", através de quem se constrói o sujeito do discurso.

Diga pelo menos de forma indireta, para isso você tem estilo. Não, de forma indireta ele já não quer. Hoje o humor e o bom estilo estão desaparecendo e se aceitam insultos em vez de gracejos (Dostoiévski, 2005:15).

Em Bobók, o discurso direto é largamente usado, assim como o indireto livre, e, por vezes, as vozes se confundem de tal maneira que difícil é saber se fala o eu ou o outro. Assim, não se sabe se é a voz do narrador aconselhando, ou se ele é aconselhado a dizer de forma indireta. Após, há uma refutação: "Não, de forma indireta ele já não quer”. Também é difícil reconhecer o ele, a quem se refere. Por fim uma crítica, sem pretensões moralizantes, é feita aos dias em que o narrador vive ("hoje”).

A narrativa de Bobók é a história de uma pessoa, Ivan Ivánitch, que escuta vozes em seu ouvido: "bobók, bobók, bobók....”". Sai para se divertir e acaba num enterro, onde começa a ouvir vozes. Raramente sóbrio, escritor fracassado: "Na semana passada enviei a uma única redação a quadragésima carta em dois anos (Dostoiévski, 2005:16)”. Ivánitch se queixa de sua época, que, segundo ele é sem humor e estilo. A voz do outro é claramente ouvida nos discursos de Ivan Ivánitch, não só pelo grande número de discursos direto que reproduz, pois a maior parte da narrativa é ocupada pelo diálogo dos mortos, em que Ivan pouco se manifesta, mas também pelo uso do indireto livre: "diz que de cultivo próprio”; “diz que é um fenômeno" (Dostoiévski, 2005:12).

Esse "diz que" (díeskat) é um recurso que introduz a palavra do outro numa espécie sutilíssima de indireto livre muito comum na linguagem oral russa. (Bezerra, 2005:98). Essa "uma pessoa" constrói o próprio discurso como um pêndulo que oscila entre a aceitação e resistência à palavra do outro: "O problema é que eu preciso escutar de toda parte e não só de um lado para fazer uma idéia” (Dostoiévski, 2005:38). 
De tanto ser recusado pelos editores, Ivan escreve sob encomenda coisas como A arte de agradar às mulheres, provável manual de comportamento e ajuda, cujo estilo de gênero muito difere do estilo da narração de Bobók. Se aqui temos vozes eqüipolentes, ali temos a voz de um enunciador que fala do alto, construindo para si a imagem do sujeito competente, que sabe, investido do poder de transmitir o seu saberfazer para alguém que não pode e que não sabe. Ivánitch, para conseguir algum dinheiro, faz panegíricos, discursos de louvor a alguém, encomiástico. Este gênero de discursos (encomiástico) a sátira menipéia tem por objeto parodístico, como prova o Moriae Encomium, o famoso elogio da loucura, de Erasmo de Roterdã. E, lembremos, Bakhtin define Bobók como "uma das mais grandiosas menipéias de toda literatura universal” (Bakhtin, 1981:118), propiciando uma leitura parodística de toda narrativa de Bobók, através da constituição da figura do narrador. Ivan Ivánitch quer reunir os aforismos de Voltaire, mas crê que isso pareça insosso aos atuais leitores, pois o tempo, afirma, é de palerma, não de Voltaire. "Vivo a fazer sermões e sugestões, a criticar e indicar o caminho” (Dostoiévski, 2005:16): essa uma pessoa é uma multiplicidade de vozes polêmicas, até polemizar finalmente com os “mortos contemporâneos”. Certa vez, falou-lhe um amigo:

Teu estilo, diz ele, está mudando, está truncado. Truncas, truncas, e sai uma oração intercalada, após a intercalada vem outra intercalada, depois mais alguma coisa entre parênteses e depois tornas a truncar, a truncar [...] (Dostoiévski, 2005:18).

A questão do estilo é fundamental, não só para esses escritores criados por Dostoiévski, mas para muitos de seus personagens também. Em Pobre Gente (1846), romance escrito através de cartas de seus personagens, tipo de narração em primeira pessoa também, o herói queixava-se do próprio “mau estilo”. Goliádkin, personagem central de $O$ duplo (1846), mas que não tem a função de ator-narrador, lamenta-se de “não ser forte na oratória”. Nos atores-narradores que também são actantes narrativos a questão torna-se mais latente, pois estes têm de representar o mundo e a si mesmos através das próprias palavras.

O discurso e as expressões caóticas estão ligados ao estado em que se encontram os narradores e personagens considerados, a aceitação, resistência e refutação da palavra do outro. Como diz o tradutor de Bobók: "a articulação sinuosa de sua linguagem está em homologia com o modo sinuoso como ele resiste à palavra do outro” (Bezerra, 2005:44).

Mas, por outro lado, afirmar o eu do outro seria a tarefa dos heróis de Dostoiévski, pois na representação polifônica, o outro, outras personagens do discurso, não são objeto da representação monológica de um autor, em um mundo unívoco, mas sim sujeitos do próprio discurso significante em um mundo de choque de diferentes pontos de vista; nenhuma consciência representada se converteu em objeto da outra, “essa interação não dá ao contemplador a base para a objetificação de todo um evento segundo o tipo monológico comum [...] mas faz dele um participante” (Bakhtin, 1984:13).

Nós, interlocutores da mensagem poética, damos-lhe sentido, mas não podemos jamais restringir seus significados, englobando as oposições dialógicas em uma consciência monologicamente abrangente, a própria forma não nos permite isso. $\mathrm{O}$ 
narrador da narrativa polifônica, diferentemente da representação monofônica, não nos dá uma última palavra em relação a uma personagem, não proporcionando, portanto, a definição, a visão de completude, o sentido final de uma vida. Na polifonia há uma guerra pela posse da última palavra, e pela definição última, formadora e limitadora. A palavra do herói é sempre responsiva: a outras vozes narrativas, ao já narrado, ao leitor, não se delimitando nunca. O Outro é o juiz, sanciona-o, sempre na consciência Ivan. Daí a voz esquiva: esses personagens polifônicos de Dostoiévski não-querem ser exteriormente sancionados. O discurso construído é com mirada, murando-se do ataque externo.

O discurso fragmentado e caótico também está ligado à representação de um mundo assim fragmentário e caótico, de desagregação, pelas mudanças estruturais por que passava a Rússia. Nessa época, a crescente europeização do país acabou gerando um conflito entre a corrente ocidentalista e a filoeslavista, esta afinada com o czarismo e a igreja ortodoxa. A relação da Rússia, e dos russos, com as maneiras dos outros povos ocidentais, as heranças da época de Pedro, o Grande, que introduziu mudanças europeizantes na Rússia, e o destino posterior do país, é tema e preocupação de Dostoiévski. Para o escritor (Notas de inverno sobre impressões de verão, 1863, sobre as impressões de sua primeira viagem à Europa), as mudanças europeizantes não mudaram o caráter desigual e violento da sociedade aristocrática feudal russa. Nem as reformas burguesas de 1861, que aboliram o estatuto da servidão. O sistema feudal russo ruía e levavam-na a uma encruzilhada entre o sistema capitalista europeu e a tentativa de um sistema baseado nas idéias socialistas, e, conseqüentemente, às mudanças das relações de trabalho e de classe.

Na narrativa de Bobók a progressão temporal acelerada em direção a um futuro instala a possibilidade do acontecimento insólito, devido à expectativa da mudança e do acontecimento - “O caráter está mudando, a cabeça está doendo” (Dostoiévski, 2005:18) -, percebido na própria justaposição de termos opostos, como o divertimento e a morte: “Saí para me divertir, acabei num enterro” (Dostoiévski, 2005:18).

Toda uma elipse de acontecimentos, que pela aproximação de início e fim da ação causam o efeito cômico. O tempo da crise, da desestabilização, abre espaço para o aparecimento do diálogo dos mortos. Na narrativa, caminha-se através de símbolos carnavalescos justapostos, perfazendo a ambivalente combinação de morte-risobanquete:

a) a atitude familiar e profana em relação ao cemitério: "só me faltava um lugarzinho assim” (Dostoiévski, 2005:18);

b) ambivalência entre dor e alegria: "Muitas caras tristes, e também muita dor fingida, e muita alegria franca” (Idem, 2005:18-19);

c) rebaixamento do poder (tema fortemente retomado durante o diálogo dos mortos): "Comecei a caminhar entre as sepulturas. Classes diferentes [...] Na terceira classe enterraram desta vez umas seis pessoas, entre eles o general e a grã-fina” (Idem, 2005:19);

d) banquete: “comi uns salgadinhos e tomei um trago” (Ibidem). 
Após uma divagação sobre o tema da admiração e novamente sátira ao discurso do bom-tom, importante para a compreensão sobre esses valores para o narrador, também ligado a discursos de alguns mortos, continua o narrador "Nisto comecei a dormitar (Dostoiévski, 2005:19)”, e então, temos uma ação que poderia ser comparada com um rito carnavalesco: Ivan esfarela pão sobre a terra (semeadura e fecundação) mas diz que não se pode esfarelá-lo sobre o chão (seio estéril).

Gênero das últimas questões, a ação menipéica não ocorre apenas aqui e agora, mas em todo lugar e na eternidade: do curso temporal de uma vida que já se afasta do decurso temporal bibliográfico, a vida de Ivan, cuja representação temporal é a da expectativa iminente do acontecimento e o tempo de crise, não a acumulação temporal da formação, até o tempo dos mortos no diálogo, que curiosamente não é toda a eternidade, mas “dois ou três meses... às vezes até meio ano” (Idem, 2005:34), que serão aproveitados em "outras bases": "Sugiro que passemos esses dois meses da maneira mais agradável possível” (Ibidem).

Momento último dos lampejos de consciência, momento da morte, instante capaz de condensar toda a história de uma vida e momento final da possibilidade de formação e configuração de um caráter. Exatamente esse último lampejo de consciência e revelação final de um caráter será problematizado na representação polifônica, pois é o momento da definição, da conclusão, e os heróis de Dostoiévski são da ordem do inacabamento, rejeitam ser conformados e definidos à revelia. O instante último é estendido (podendo ser comparado com a eternidade, mas numa má infinitude, no caso de Bobók) e não totalmente concluído, nem através da narrativa (um espirro de Ivan interrompe o diálogo), nem através da consciência das personagens.

Rompem-se (ou pelo menos se debilitam por um instante) as "cordas podres" da mentira oficial e individual e revelam-se as almas humanas, horríveis como no inferno ou, ao contrário, radiantes e puras. Por um instante as pessoas se vêem fora das condições habituais de vida, como na praça pública ou no inferno, e então se revela um outro sentido - mais autêntico - delas mesmas e das relações entre elas (Bakhtin, 1981:125).

O tempo é o da revelação dos caracteres. Findo o diálogo dos mortos contemporâneos Ivan pensa em publicá-lo num semanário, apesar da experiência o narrador apenas volta ao seu antigo querer folhetinesco, confirmando o não-alinhamento da narrativa a um aprendizado do tempo biográfico. A oposição entre aristocracia X jogo capitalista pode ser encontrada em Bobók, já que, na parte do diálogo dos mortos, o general com seus símbolos aristocráticos é destronado:

- Eu servi ao meu soberano... tenho uma espada...

- Vossa espada serve para espetar ratos, e além do mais o senhor nunca a desembainhou.

[...]

— Eu não entendo o que é uma espada - proclamou o engenheiro.

- Nós vamos fugir dos prussianos como ratos, eles nos reduzirão a pó! Gritou uma voz distante, estranha a mim, mas literalmente sufocada de êxtase.

- A espada, senhor, é honra! - ia gritando o general, mas só eu o ouvi. Ergueu-se uma berraria demorada e frenética, motim e alarido, e só se ouviram os guinchos impacientes e quase histéricos de Avdótia Ignátievna (Dostoiévski, 2005:37). 
A espada do general, e consequentemente sua significação de honra, é ridicularizada, e a voz dele abafada pelos gritos. A oposição se percebe também no conceito de honra, já que para um personagem o general nunca a desembainhou, não obstante a espada ter servido para espetar ratos, e então uma voz anônima constrói a imagem de russos como ratos ("nós vamos fugir dos prussianos como ratos”), também mostrando um aspecto da confusão de vozes. Dizer que o general nunca desembainhou sua espada é uma afronta à honra dele e à necessidade de uma espada. O engenheiro, por sua vez, nem entende o que é uma espada.

Só no Épico a representação do tempo da narrativa está separada de todos os tempos posteriores, inclusive o do ouvinte e do aedo, ela está afastada do devir, que é inacabado, daí seu caráter perfectivo, pleno, fechado, acabado. Em Dostoiévski não existe a palavra primordial (origem perfeita), e a última ainda não foi dita. Na épica temos uma personagem concluída num nível altamente heróico, que coincide consigo próprio e é igual a si mesmo, completamente exteriorizado, entre sua essência e seu aspecto exterior não há a menor discrepância. Há uma coincidência de pontos de visitas entre personagens, o ponto de vista de uma personagem sobre si mesmo é exatamente o ponto de vista dos outros sobre ele.

Estas particularidades do homem épico (...) originam a beleza excepcional, a coesão, a claridade cristalina e o polimento literário desta representação do homem, mas, por outro lado, elas também engendram a sua limitação e uma certa irrealidade nas novas condições da existência humana (Bakhtin, 2002:424).

Uma ingenuidade, na verdade absoluta, que Bakhtin destrói ao colocar a interação entre consciências, confronto de idéias, tempos e pontos de vista, como o objeto de estudo, e ressaltemos que isso não para relativizar tudo, pois assim qualquer diálogo autêntico estaria excluído de sua razão de ser, e nem dogmatizar, pela mesma explicação, mas sim para revelar uma verdade construída na relação e interação entre indivíduos, uma verdade dialógica, mostrando o falso equilíbrio do indivíduo isolado. Temos o postulado do dever ético com o outro, o indivíduo que contrai relações de reciprocidade com outros indivíduos, realizando o ethos no e pelo pathos. Podemos aqui citar os Irmãos Karamazov, de Dostoiévski - quando um visitante misterioso pergunta ao stárietz ${ }^{2}$ Zossima (personagem do romance) quem escreveu: "Em verdade, em verdade vos digo: se o grão de trigo, caindo na terra, não morrer, fica ele só; mas se morrer, produz muito fruto”, e ele responde: “O Espírito Santo” (Dostoiévski, 1976:281), um momento de paraíso carnavalesco - e contrastar com os "mortos atuais”, do diálogo dos mortos de Bobók, com sua "perversão em um lugar como este, perversão das últimas esperanças, perversão de cadáveres flácidos e em decomposição, sem poupar sequer os últimos lampejos de consciência” (Dostoiévski, 2005:38).

Em Bobók, os “mortos atuais” são grãos estéreis lançados na terra mas incapazes de morrer (ou seja, de livrar a si mesmo de suas próprias impurezas, de colocar-se acima de si mesmo) ou renascer renovados (ou seja, dar fruto) (Bakhtin, 1981:127).

Mostrando mais uma vez a impossibilidade de se construir com e através do outro em alguns mundos discursivos de Dostoiévski. As barreiras impostas à 
comunicação entre as pessoas são infringidas em alguns momentos por Dostoiévski, numa tentativa desesperada de configuração artística da linguagem; mas por vezes nem mesmo no momento propício da destruição dessas barreiras ainda se é capaz de estabelecer uma comunicação entre todos, como no caso dos mortos de Bobók: O diálogo dos mortos escutados por Ivan começa com um jogo de baralho no vazio entre um general e o bajulador dele e as cartas têm de ser dadas por baixo da mesa. Mais uma vez o jogo, que carrega consigo os traços da carnavalização. Mas a bajulação ainda existe, mostrando ainda a permanência do poder das relações de força, ditadas pelo mundo "lá de cima”. Os dois são os mais maçantes e não sabem falar de nada em que não haja ideal, segundo uma personagem, que logo emenda, falando para o general: "Conheço aquela historiazinha em que o criado vos varreu com a vassoura de debaixo da cama de um casal ao amanhecer” (Dostoiévski, 2005:25).

No carnaval que se arma, porém, o general é destronado. O rei carnavalesco será agora o Barão Kliniêvitch, "pulha da pseudo alta sociedade”, que desfalcou lá em cima dinheiro público destinado aos órfãos e velhinhas. Propõe que não se envergonhem de nada, se dispam, "vivam” esses dois meses sem nenhuma mentira, "na mais desavergonhada verdade", para se divertirem, pois "Na Terra é impossível viver e não mentir” (Idem, 2005:35). Os mortos se agitam, com urros e gritos histéricos: "Estou com uma terrível, uma terrível vontade de tirar a roupa!” (Ibidem), mas ainda escutamos vozes díspares: "Não eu ainda gostaria de viver, não ficai sabendo, eu ainda gostaria de viver!” (Ibidem), ou: “Nem no túmulo nos deixam em paz!” (Idem, 2005:36).

No tempo dos últimos lampejos de consciência instala-se o carnaval, uma cena de inferno carnavalesco. No tempo do túmulo e dos últimos lampejos poderíamos vislumbrar uma completude e revelação dos caracteres, mas essa visão não nos é dada, eles se revelam de maneira subvertida, não em completude. O presente também é configurado como evento incabado.

Portanto, a experiência que visa encontrar um ponto firme em nós mesmos, para no fim saber quem nós somos, é uma tentativa desesperada: uma tentativa desesperada de demolir a muralha chinesa que construímos entre Eu e Você, entre o eu e o mundo externo. É uma tentativa desesperada e sempre inútil. Durante a experiência, exprime-se, na mais pura das suas formas, a tragicidade - ou a tragicomicidade - do homem solitário (Lukács, 1965:153).

A nova forma desse gênero "polifônico" conduz a uma nova representação do próprio homem, que deve ser analisada, pois:

[o fato] é aqui apresentado na linguagem da arte e, particularmente, na linguagem de uma variante específica do gênero romanesco. É necessário mostrar antes de tudo as peculiaridades de construção desse romance multiplanar, despojado da costumeira unidade monológica (Bakhtin, 1984:15).

O personagem de Dostoiévski não coincide consigo mesmo, há uma discrepância entre os seus diversos aspectos, e o próprio enredo deixou de revelar o homem por inteiro. Os pontos de vistas que os outros personagens fazem dele, e também o narrador, não coincidem entre si, e nem com a opinião da própria personagem sobre ela mesma. A motivação do herói de Dostoiévski é formar para si uma imagem que ele mesmo julgue condizente consigo. A personagem de Dostoiévski constrói a 
imagem de si através do outro. Esse é um aspecto da polifonia de Dostoiévski: com o presente configurado como evento inacabado na narrativa, não é possível um distanciamento configurativo suficiente da representação, para uma palavra que conforme em sua totalidade a vida e a imagem da personagem, resultando assim em um inacabamento tanto temporal quanto da construção dos atores.

O narrador dá mostras de insegurança sobre o seu saber. Apagando-se e confundindo sua voz com a dos personagens. No plano polifônico, a personagem pode ultrapassar os limites de sua própria tipicidade e temperamento, ela já sabe tudo o que podemos dizer a respeito dela, e assim pode, portanto, nos contradizer.

Sabe também que todas essas definições, sejam parciais ou objetivas, estão em suas mãos e não lhe concluem a imagem justamente porque está consciente delas; pode ultrapassar-lhes os limites e torná-las inadequadas. Sabe que lhe cabe a última palavra e procura a qualquer custo manter para si essa última palavra sobre si mesmo, essa palavra da autoconsciência, para tornar-se nela não mais aquilo que ela é (Bakhtin, 1984:45)

O que o personagem deseja é tornar-se sujeito do próprio discurso plenamente significante, não apenas ser um objeto de análise. Se podemos reconhecer um objeto de valor para Ivan, será a vontade de não ser definido, objetificado. Ele sabe que há nele sempre algo que ele mesmo pode descobrir no ato livre de seusdiscursos e autoconsciência, por isso rejeitam definições à revelia e exteriorizantes. Essa luta é o motivo trágico da existência dos personagens de Dostoiévski: querer ser o sujeito de seu discurso plenamente significante. Também sobre tal valor podemos unir a obra de Bakhtin: o dialogismo. A percepção e a vontade do homem de não ser objeto passivo do discurso alheio, mas sujeitos da significação, problema semiótico.

\section{NotAs}

\footnotetext{
${ }^{1}$ Significa "fava”, em russo.

${ }^{2}$ Monge
} 


\section{REFERÊNCIAS BIBLIOGRÁFICAS}

BAKHTIN, Mikhail. Problemas da poética de Dostoiévski. Rio de Janeiro: Ed. Forense Universitária, 1981.

. Questões de Literatura e Estética. São Paulo: Hucitec, 2002.

BARROS, Diana Luz de. Teoria do discurso - Fundamentos semióticos. São Paulo: Humanitas, 2001.

BEZERRA, Paulo. “Um romance profecia”. Posfácio a Dostoiévski. In: . Os demônios. São Paulo: Editora 34, 2004. 2005.

Dostoiévski: "bobók" tradução e análise do conto. São Paulo: Editora 34,

DOSTOIÉVSKI, Fiódor. Os irmãos Karamazov. Ed. Naúka, 1976.

Bobók. São Paulo: Editora 34, 2005.

LUKÁCS, Georg. Ensaios sobre literatura. São Paulo: Civilização Brasiliense S.A., 1965.

SAMOSÁTA, Luciano de. Diálogo dos mortos. São Paulo: Edusp, 1996.

Como citar este artigo:

SERPA, Danilo Chiovatto. Análise do discurso de Bobók, de Dostoiévski. Estudos Semióticos. [online] Disponível na Internet via WWW.URL: http://www.fflch.usp.br/dl/semiotica/es. Editor Peter Dietrich. Número 4, São Paulo, 2008.

Acesso em "dia/mês/ano". 